\title{
The stressed prefrontal cortex. Left? Right!
}

\author{
João J. Cerqueira, Osborne F.X. Almeida, Nuno Sousa * \\ Life and Health Sciences Research Institute (ICVS), School of Health Sciences, University of Minho, Braga, Portugal \\ Max Planck Institute of Psychiatry, Munich, Germany
}

Received 1 December 2007; received in revised form 4 January 2008; accepted 5 January 2008

Available online 20 February 2008

\begin{abstract}
The prefrontal cortex (PFC) plays an important role in the integration of cognitive and affective behavior and regulating autonomic and neuroendocrine functions. This region of the brain, which may be considered analogous to the RAM memory of a computer, is important for translating stressful experience into adaptive behavior. The PFC responds to stress and modulates the response to stress through regulation of the hypothalamic paraventricular nucleus (PVN) which, in turn, controls sympathoadrenal and hypothalamicpituitary-adrenal (HPA) activity. Interestingly, the latter convey the signals that link the CNS with the immune system.

The present review highlights findings that contribute to elucidate the involvement of the PFC in the control of behavioral and neuroendocrine responses to chronic stress. It also considers the implications of these regulatory links for disorders of the nervous and immune systems.
\end{abstract}

(C) 2008 Elsevier Inc. All rights reserved.

Keywords: Prefrontal cortex; Stress; HPA axis; Hippocampus; Handedness; Hemispheric asymmetry; Lateralization; Immune response; Autonomic nervous system

\section{Introduction to the prefrontal cortex (PFC)}

Effective communication requires a code that is comprehensible to both the transmitter (the author) and the receiver (the reader). Accordingly, we will approach this task keeping in mind Leonardo da Vinci's words "simplicity is the ultimate sophistication" or those of Albert Einstein "make things simple ... but not simpler".

The PFC was defined after Brodmann's pioneering classification of the cortex. It includes all areas of the frontal lobe that have an inner granular layer IV and lie rostral to the agranular (pre)motor region. These areas, which are well-developed in man, consist of several anatomically distinct subfields, roughly divided into dorsolateral, medial (anterior cingulate) and orbital regions (Fuster, 1997). Different cognitive and emotional functions have been

\footnotetext{
* Corresponding author. Address: Escola de Ciências da Saúde, CP II Piso 3, Universidade do Minho - Campus de Gualtar, 4710-057 Braga, Portugal. Fax: +351 253604809 .

E-mail address: njcsousa@ecsaude.uminho.pt (N. Sousa).
}

ascribed to these subdivisions of the primate PFC (Goldman-Rakic, 1995). Work by Damasio and co-workers in lesioned patients has led to the view that the PFC is involved in working memory, decision making, planning and behavioral flexibility, as well as in social interactions and emotional processing (Damasio, 2000).

It was previously inferred from the large size of the primate (especially human) frontal lobes that the PFC is a uniquely primate structure. However, based on the common patterns of connectivity among all mammals, the predominance of reciprocal relations with the mediodorsal nucleus of the thalamus and the existence of "class-common functions", such as working memory, temporal organization of behavior and social skills, a region at the frontal pole of the rat brain is now widely considered to be the rodent equivalent of the primate PFC (Uylings et al., 2003). The areas that constitute the rat PFC can be grossly grouped into two main subdivisions: a medial region (mPFC, comprising frontal area 2 (Fr2), dorsal and ventral anterior cingulate areas $(\mathrm{ACd}$ and $\mathrm{ACv})$, prelimbic area (PL), infralimbic area (IL) and medial orbital area (MO)) 
that has characteristics of the human dorsolateral and medial PFC, and a lateral and ventral region (OFC, comprising dorsal agranular insular area (AId), ventral anterior insular area (AIv), lateral orbital area (LO) and ventral orbital area (VO)) that resembles the primate orbitofrontal cortex (Zilles and Wree, 1995; Dalley et al., 2004).

The PFC has extensive connections with the thalamus (particularly the mediodorsal thalamic nucleus) and basal ganglia (Uylings et al., 2003), its different parts being involved in various basal ganglia-thalamo-cortical circuits. Of particular importance is the input from the midline thalamic nuclei to ventral mPFC areas (IL and PL) through which subcortical limbic information, including from the hypothalamus, is conveyed to the PFC. Available data suggest that the PFC has also extensive, mainly ipsilateral, connections with the other cortical areas, including the hippocampus (CA1 and subiculum). While for long considered a homogeneous region, histochemical and connectivity studies have revealed that the PFC represents a group of distinct areas. Of notice, each of these regions has generally distinct functions (see Table 1).

Furthermore, there is consensus that the dorsal (composed by the prelimbic (PL) and anterior cingulate $(\mathrm{Cg}))$ and ventral (mainly infralimbic (IL)) portions of the rat $\mathrm{mPFC}$ are, in fact, two distinct sub-areas (Uylings et al., 2003), although correspondence with equivalent regions in the primate brain remains to be established. For example, the ventral (IL) and dorsal (PL/Cg) zones of the mPFC appear to have opposing effects in the expression of emotional behaviors such as avoidance of aversive outcomes (Jinks and McGregor, 1997), conditioned fear (Vidal-
Gonzalez et al., 2006) and habit formation (Killcross and Coutureau, 2003). Importantly, our understanding of the pathogenesis of mood and emotional disorders has changed remarkably since the demonstration of the impact of stress in the aetiology of these disorders (see Sheline, 2000). We have recently gained insights into the interplay between the hippocampus, amygdala/bed nucleus of the stria terminalis (BNST) and mPFC in rats (Sousa et al., 2007). Briefly, stress-induced changes in the hippocampus downgrade some PFC functions (Cerqueira et al., 2007a), allowing the amygdala/BNST (responsible for coordinating emotive responses to stimuli) to assume a dominant function (Fig. 1). These findings are consistent with imaging and post-mortem histological studies that describe alterations in these brain areas of patients suffering from chronic anxiety and depression.

As with its regulation of emotional behavior, the ventral and dorsal PFC areas exert a dual control over the autonomic system. Electrical stimulation of more dorsal zones (prelimbic/anterior cingulate), activates the parasympathetic system, whereas stimulation of the ventral zone (IL) typically elicits sympathetic responses (Powell et al., 1994). Interestingly, human patients with damage in the ventromedial PFC fail to show autonomic responses to emotionally-charged stimuli and exhibit greatly impaired emotional and social functioning, decision-making and risk assessment (Damasio, 2000). Moreover, fMRI studies have documented the activation of $\mathrm{MPFC}$ regions by procedures that evoke autonomic changes (Harper et al., 2000).

The PFC appears to be strategically positioned to modulate cognitive and emotional responses to stress. Summa-

Table 1

Behavioral impairments observed after lesions of the two major divisions of the PFC (Adapted and abridged from Uylings et al., 2003 and Chudasama and Robbins, 2006)

\begin{tabular}{|c|c|}
\hline Behavioral impairment & Key references \\
\hline \multicolumn{2}{|l|}{ mPFC lesions } \\
\hline Spatial working memory & Kolb et al. (1974), Ragozzino et al. (1998) \\
\hline Strategy formation & Kolb et al. (1994), Chudasama et al., (2001) \\
\hline Spatial reversal & Divac (1971), Delatour and Gisquet-Verrier (2000), Chudasama and Robbins (2003) \\
\hline Habituation & Kolb $(1974 a)$ \\
\hline Skilled reaching & Whishaw et al. (1992a) \\
\hline Motor sequencing & Kolb and Whishaw (1983) \\
\hline Attention & Muir et al. (1996), Chudasama et al. (2003) \\
\hline Attention set shift & Birrell and Brown (2000), Barense et al. (2002) \\
\hline Food hoarding & Kolb et al. (1974b) \\
\hline Fear extinction & Quirk et al. (2000) \\
\hline Conditioned emotional responses & Frysztak and Neafsey (1994) \\
\hline Spontaneous alternation & Wikmark et al. (1973) \\
\hline Decision making & Haddon and Killcross (2006) \\
\hline Motor responses to pain & LaBuda and Fuchs (2005) \\
\hline \multicolumn{2}{|l|}{ OFC lesions } \\
\hline Hyperactivity & Kolb $(1974 c)$ \\
\hline Social behavior & Kolb (1974d), de Bruin (1990) \\
\hline Incentive association & Gallagher et al. (1999), Schoenbaum and Setlow (2001) \\
\hline Odor and taste working memory & Otto and Eichenbaum (1992), Ragozzino and Kesner (1999) \\
\hline Configural odor learning & Whishaw et al. (1992b) \\
\hline Feeding & Kolb and Nonneman (1975) \\
\hline Impulsivity & Mobini et al. (2002), Winstanley et al. (2004) \\
\hline
\end{tabular}


BASAL CONDITIONS

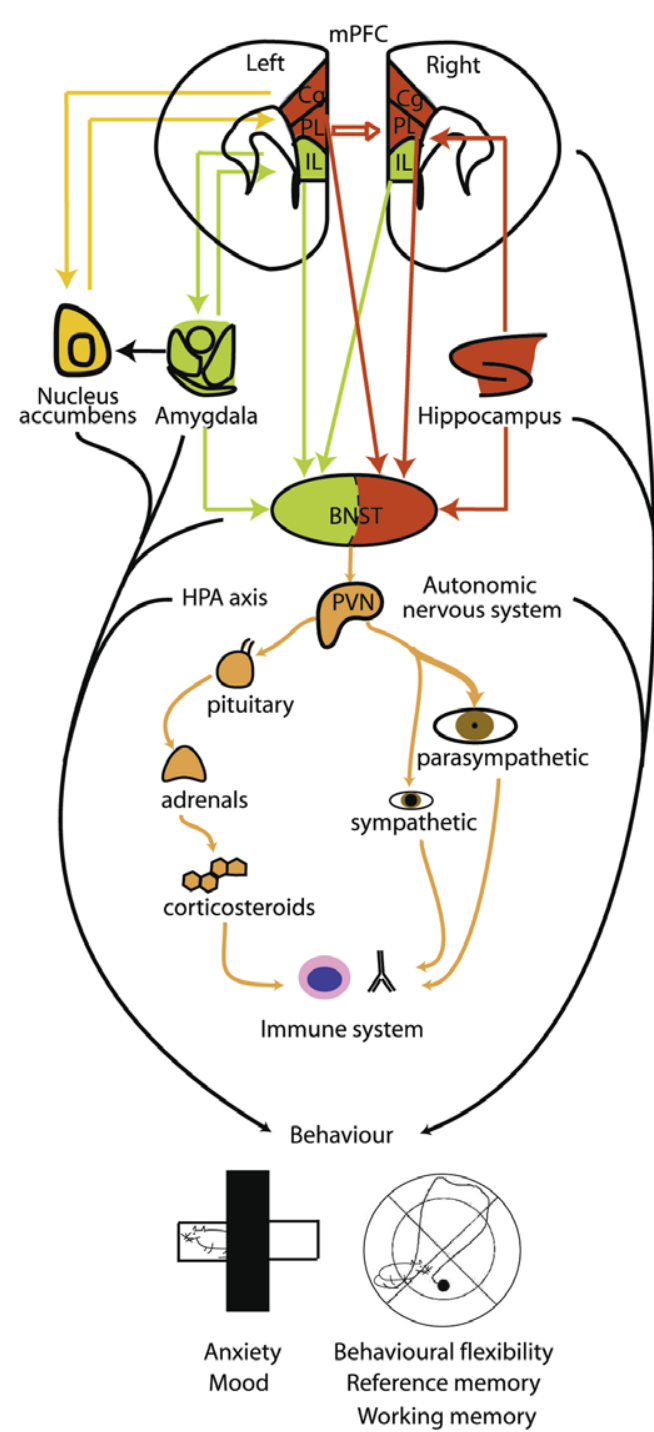

AFTER CHRONIC STRESS

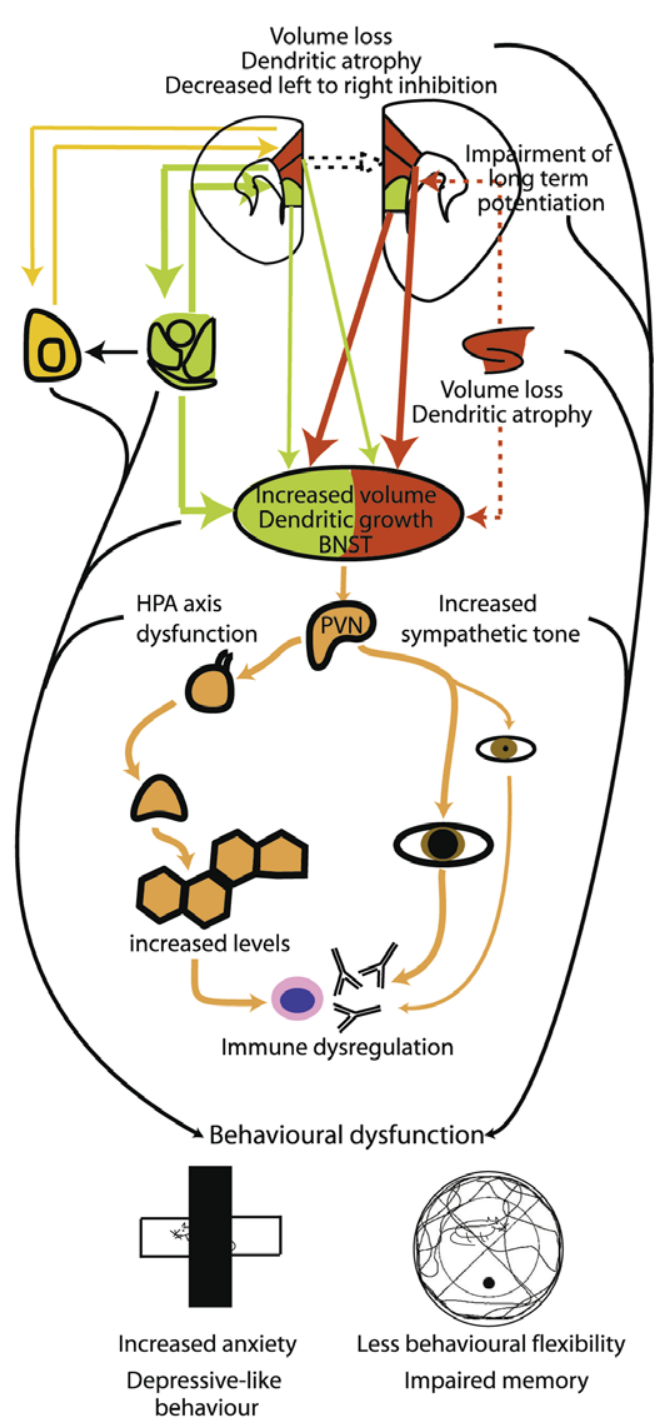

Fig. 1. Connections between the prefrontal cortex, the stress response and the immune system. In basal conditions (top panel) the right medial prefrontal cortex (mPFC) is under tonic inhibition from its left counterpart. Note that modulatory inputs from the mPFC, amygdala and hippocampus to the paraventricular nucleus of the hypothalamus relay on the bed nucleus of stria terminalis (BNST). Furthermore, whereas activation of the infralimbic cortex (IL) and amygdala increases paraventricular nucleus of the hypothalamus (PVN) activity, activation of the cingulate (Cg) and prelimbic (PL) cortex and the hippocampus decreases it. In basal conditions the parasympathetic tone predominates. After chronic stress (lower panel), changes in the stress response network of the brain include decreased volume and dendritic atrophy in the MPFC and hippocampus, but opposite changes in the BNST. Damage to the hippocampus will decrease the influence of this brain structure in the mPFC and BNST (dotted lines); as a result, there is a reduced activity of mPFC (specially in the left hemisphere), but an overactivation of the amygdala, over the neuroendocrine and autonomic control centres (BNST/ hypothalamus). These stress-induced changes trigger HPA axis dysfunction, resulting in increased corticosteroid levels, and sympathetic activation which may induce immune dysregulation and contribute to behavioral dysfunction.

rising from the above-described anatomical and functional studies, one may conclude that the rodent PFC is subdivided into a ventrolateral area that plays a central role in the control of socio-affective behaviors, a dorsomedial ( $\mathrm{PL}$ and $\mathrm{Cg}$ ) area that regulates working memory and some forms of motor sequencing, and a ventromedial (IL) area that is primarily involved in visceromotor behaviors. The two latter subdivisions are considered to represent the rodent $\mathrm{mPFC}$. The $\mathrm{mPFC}$ receives diverse afferent inputs from limbic regions, including the amygdala and ventral hippocampus/subiculum, and provides direct outputs to hypothalamic and numerous brainstem areas involved in the regulation of emotion and in the physiological response to stress (Bandler et al., 2000).

\section{The role of the PFC in the regulation of the stress response}

Frankel and Jenkins (1975) and Feldman and Conforti (1985) first demonstrated that stimulation of the PFC increases plasma corticosterone (CORT) levels. Since 
then we have learnt that the contribution of the PFC in regulating the Hypothalamo-Pituitary-Adrenal (HPA) axis is more complex than initially predicted. For example, the endocrine response to restraint stress, but not ether-induced stress, is attenuated in rats with $\mathrm{mPFC}$ lesions (Diorio et al., 1993), and the endocrine response is lost in animals challenged with IL-1 $\beta$ but not air-puff stress (Spencer et al., 2004). These observations suggest that the mPFC stimulates the HPA axis responses in a stimulus-specific manner. Distinct roles of the different subdivisions of the mPFC in the control of the HPA axis have also been suggested in terms of opposing functions for the ventral and dorsal portions of the mPFC in the regulation of behavioral and physiological responses to stress. Thus, these responses seem to be enhanced by the IL (Sullivan and Gratton, 1999; Sullivan, 2004; Radley et al., 2006), and suppressed by the more dorsal subareas (Diorio et al., 1993; Sullivan, 2004; Radley et al., 2006).

Interestingly, these regulatory actions of the $\mathrm{mPFC}$ seem to originate from within the right hemisphere since, as extensively reported by Sullivan and Gratton (1999, 2002), the outcome of bilateral lesions can be faithfully reproduced by unilateral lesions of the right $\mathrm{mPFC}$, but not of the left mPFC. These observations of hemispheric regulatory dominance are consistent with results showing that the left brain may work to inhibit right-side-dependent stress-related emotional expressions using interhemispheric inhibition (Denenberg, 1983; Sullivan, 2004). This issue will be returned to later in this article.

Importantly, the control of the mPFC upon the HPA axis is impaired when animals are subjected to chronic stress. Sullivan and Gratton (1999) reported a blunting in the peak of adrenocortical (CORT) secretory response after 4 weeks of restraint stress (habituation), an effect that was accentuated when the mPFC was lesioned. Moreover, the ability of systemic or intra-mPFC administered dexamethasone (DEX, a specific glucocorticoid receptor [GR] agonist) to inhibit CORT secretion was seen to be significantly attenuated in animals exposed to chronic stress (Mizoguchi et al., 2001, 2003). This failure of DEX to suppress the HPA axis is reminiscent of the situation found in a substantial proportion of patients with mood disorders (e.g., major depression) (Carroll et al., 1980; Tichomirowa et al., 2005).

In summary, it appears that the mPFC adjusts behavior, neuroendocrine and autonomic responses to stressful situations according to a specific pattern (Fig. 1). Dorsomedial regions tend to dampen behavioral reactivity, enhance parasympathetic system activity and reduce HPA activation, while ventromedial areas (mainly IL) stimulate emotional behavior, sympathetic system activation and HPA function. The ventral division of the mPFC seems to play a more important role in the initial adjustment to stress whereas the more dorsal areas of the PFC come into play later when they refrain the activity of the IL.

\section{Impact of chronic stress in the PFC}

The impact of stress on the brain has received much attention from both the neuroscience and lay communities. However, studies in this field have been almost entirely devoted to an analysis of stress effects on the hippocampal formation (for review, see Sousa et al., 2007). More recently, the influence of chronic stress on PFC structure and function has been addressed. Of notice, it has been shown that chronic stress impairs spatial working memory (Cerqueira et al., 2007a). Working memory, defined as the ability to transiently hold and manipulate information "on line" and to use it to guide behavior (Goldman-Rakic, 1995), is considered a distinctive function of the PFC. Accordingly, performance in working memory tasks is considered the gold standard for assessing PFC functional integrity. In addition, behavioral flexibility, another paradigm of PFC function, is also impaired by chronic stress (Cerqueira et al., 2007a). Importantly, these cognitive deficits are correlated with significant volume reductions (but not neuronal loss) in superficial layers of the PFC, probably mediated by increased levels of CORT, since the region-specific parenchymal atrophy observed after chronic stress can be reproduced by chronic administration of exogenous CORT.

Parallel studies proved that stress-induced volumetric atrophy of the PFC is largely due to atrophy of apical dendrites of superficial pyramidal neurons (Radley et al., 2004; Cerqueira et al. 2007c). This selective vulnerability of the apical dendrites to manipulations of the corticosteroid environment most likely reflects the topographical distribution of inputs to layer II/III pyramidal cells of the PFC: whereas the soma and basal dendritic tree are innervated by thalamic projections (Shibata, 1993), direct afferents from limbic regions, including the hippocampus, the entorhinal cortex and the basal nuclei of the amygdala, terminate in more superficial layers (Swanson and Cowan, 1977), where they preferentially contact apical dendrites. These two fiber systems are glutamatergic and their postsynaptic actions are mediated by metabotropic (AMPA) glutamate receptors (Rudolf et al, 1996) and ionotropic NMDA receptors (Pirot et al, 1994), respectively. Interestingly, layer II of the mPFC, where the apical dendrites of pyramidal neurons are located, is abundantly endowed with extrasynaptic NMDA.R2B-containing receptors which play a crucial role in corticosteroid-induced hippocampal excitotoxicity ( $\mathrm{Lu}$ et al., 2003), but also in determining stress-induced PFC cognitive impairments (Cerqueira et al., 2007b). Current studies are assessing if NMDA.R2B antagonists can prevent stress-induced dendritic atrophy. In contrast to NMDA.R2B receptors, AMPA receptors, which transduce thalamic-to-prefrontal cortex signals, are clustered in the basal dendrites and soma, and are scarcely localized at the apical dendrite (Vickers et al., 1993). It is pertinent to note that activated AMPA receptors might serve to protect neurons against glutamate-induced neurotoxicity (Wu et al., 2004) by stim- 
ulating the expression of brain-derived growth factor (Lauterborn et al., 2000). Similarly, it is also suggested that dopamine from mesocortical afferents prevents excessive behavioral and physiological stress reactivity (Sullivan, 2004).

Another interesting aspect of the selective vulnerability of apical PFC dendrites to stress is that, as already mentioned, chronic stress targets the layers that receive most of the limbic afferent connections, including those from the hippocampus (Swanson and Cowan, 1977), resulting in altered processing of hippocampal inputs. Accordingly, we propose that the consequences of stress result more from the activation of inter-dependent brain circuits which modulate each other, rather than from independent mechanisms in individual brain areas. On the other hand, the effects of stress are highly region-specific, e.g., the gross structure of the retrosplenial cortex is not affected by alterations in the corticosteroid environment (Cerqueira et al., 2005). We suggest that the sparing of certain brain areas from the damaging effects of stress that are mediated by corticosteroids may reflect the relative expression levels of the two corticosteroid receptors. In both in vivo and in vitro studies, activation of glucocorticoid receptors (GR) induces neuronal apoptosis, whereas concomitant activation of mineralocorticoid receptors (MR) antagonizes this effect and promotes neuronal survival (Sousa et al., 2007). As a consequence, a region in which GR prevail over MR would be more affected by increased corticosteroid levels than one with balanced or predominant MR activity.

Since the effects of chronic stress in the brain seem to involve networks and to occur in a multimodal fashion, we were prompted to explore sequential communication events in two individual areas, the hippocampus and PFC. Both areas have been implicated in the activation of the stress-response circuit and, at the same time, to be subject to the actions of stress hormones (corticosteroids). Moreover, the hippocampal-PFC connection is known to be required for spatial working memory, a function that is impaired by chronic stress. This initial focus on the hippocampus-PFC pathway is not intended to relegate the importance of other regions for instance, the amygdala (Roozendaal et al., 2006), the BNST (Pego et al., unpublished observations) and the nucleus accumbens (Perrotti et al, 2004) (Fig. 1).

The hippocampus-to-PFC connection is a glutamatergic monosynaptic pathway that originates in the hippocampal $\mathrm{CA} 1$ /subiculum and terminates in the IL and Cg areas of the PFC. We recently demonstrated that chronic stress impairs the development of long-term potentiation (LTP, the electrophysiological signature of synaptic reinforcement) within this circuit (Cerqueira et al., 2007a). Synaptic plasticity, the ability to modify the strength of the synaptic communication, is one of the key mechanisms of learning and behavioral adaptation (Holscher, 1999), and plasticity in hippocampal-derived synapses on PFC neurons has been shown to be involved in PFC-dependent short-term mem- ory tasks (Laroche et al., 2000). These findings may help explain why stress induces deficits in working memory. It is of notice that peripheral activation of the innate immune system was also shown to impair working memory, an effect that was correlated with disruption of LTP induction in the hippocampal formation (Sparkman et al., 2006).

\section{4. "Side-matters!}

Rather surprisingly, volumetric reductions after chronic glucocorticoid treatment in an in vivo MRI study (Cerqueira et al., 2005) were predominantly found in the left cingulate cortex. This finding suggests that the left mPFC is more vulnerable to the effects of high corticosteroid levels and, probably, to stress. (Fig. 1) Importantly, the increased vulnerability of the left hemisphere to glucocorticoid effects was subsequently reported for the human brain; a recent MRI study associated impaired regulation of the HPA axis (hyperactivity) with a smaller left, but not right, cingulate volume (MacLullich et al., 2006). The mechanisms that underpin this increased susceptibility of the left cortex to corticosteroids remain unknown. However, it is important to note that this laterality in vulnerability to glucocorticoids/stress might represent a more general phenomenon. For instance, recent work in our lab (Silva et al., 2006) revealed that, under basal conditions, the left hippocampal dentate gyrus displays a significantly higher number of apoptotic cells than the contralateral hippocampal formation. It is important to recall that the projections between the hippocampal formation and the PFC are largely ipsilateral; these observations might be therefore interrelated.

Most cortical functions are lateralized, and at the risk of oversimplification, we would note that the majority of individuals exhibit cerebral dominance in terms of language and motor functions (left dominance), as well as in affective or emotional processing and modulation of stress response (right dominance). Similarly, Denenberg (1983) has shown that left hemisphere activation is associated with communicative functions in several species, with the right hemisphere being more active in tasks demanding spatial abilities and when affective components in the environment lead to the production of emotional responses (Denenberg, 1983). This lateralization is also present in functions typically dependent of PFC function. As an example, studies in PFC lesioned patients suggest that decision-taking abilities, a hallmark of PFC function, depend almost exclusively on the right PFC areas (Clark and Manes, 2004). It is important to remember that decision making abilities are highly dependent on emotion and the triggering of somatic markers. These are changes that occur in the body state (e.g., heart rate, bowel motility, blood pressure) when each option is being considered, assigning a positive or negative connotation to it and influencing the decision process (Damasio, 2000). Interestingly, in a functional MRI study, the right, more emotional, PFC was shown to be predominantly active when the subjects were deciding based on incomplete information, whilst the left PFC was predomi- 
nant in decisions taken with all information available (Goel et al., 2007). Of relevance, lateralization occurs early during neurodevelopment in rodents and interhemispheric interactions (activation/inhibition) are especially important when emotional processing is involved.

Hemispheric lateralization is likely to be of relevance to the aetiology of stress-related psychopathology. As already mentioned, lateralized disturbances of brain structure or function, most notably in the PFC, have been reported in patients suffering from major depressive and anxiety disorders (Davidson, 1998; Johnstone et al., 2007). Furthermore, patients with strokes in the left frontal lobe tend to have a disproportionate incidence of depression, while comparable damage to the right frontal lobe often leads to indifference, hypomania or mania (Robinson et al., 1984). This "side-effects" difference is likely to reflect the influence of each PFC in behavior. In fact, the left ventromedial PFC was shown to be selectively involved in the downregulation of negative affects, and its activation was strongly correlated with decreased activity of the amygdala (Johnstone et al., 2007). Interestingly, in the same downregulation task, depressed patients also display activation the right $\mathrm{PFC}$ regions that correlates with increased amygdala activity (Johnstone et al., 2007). These observations suggest that activation of the right PFC results in increased emotionality, an idea that is supported by the fact that when emotional stimuli are presented selectively to the right hemisphere, the raise in cortisol is remarkably greater (Wittling, 1997).

The balanced activity of both hemispheres is clinically relevant in several situations, including for the proper functioning of the immune system. This has been illustrated by studies in rodents where a general pattern of immunopotentiation has been observed following selective activation of the left hemisphere; in contrast, higher activity of the right hemisphere is accompanied by immunosuppression, indicating that both PFCs contribute to immune status (Renoux et al., 1983; Barneoud et al., 1987; Neveu, 1992; Vlajković et al., 1994). Importantly, there is also evidence for a differential role of each hemisphere in immune function in humans (Meador et al., 2004; Koch et al., 2006).

Behavioral lateralization in animals has been assessed with the paw preference model, in which the preferred anterior paw (equivalent to the "preferred hand" in humans) is defined as the one more often used by the animal to perform a standardized task (catch a food pellet in a narrow tube-for rats-or remove a piece of tape from the nose-for dogs). Using this model, several studies in rodents (Neveu and Merlot, 2003) and dogs (Quaranta et al., 2006) have confirmed the notable relationship between immune responses and behavioral lateralization, and that the activation of the HPA axis observed during the stress in response to a physical stimulus is related to lateralization. There is an association between paw preference and some immune parameters, including natural killer cell activity (Neveu, 1992), cytotoxic T lymphocyte activity, mixed lymphocyte reaction, autoantibody production, mitogen-induced lymphoproliferation (Neveu, 1992) and plasma levels of interleukin-1 $\beta$ (IL-1 $\beta$ ) and interleukin-6 (IL-6) in different strains of mice (Fu et al., 2003). Matching these experimental studies, it has been observed that human subjects with predominant left frontal neural activity show increased killer cell activity when faced with an emotion-raising stimulus and, vice versa patients with right frontal dominance display decreased killer cell activity (Davidson et al., 1999). This, together with the alreadydescribed importance of the PFC in emotional behavior and regulation of the neuroendocrine and autonomic responses to stress, suggests a strong relationship between stress and disease, including stress-related psychopathology that may be accompanied by changes in immune function (for a detailed analysis of the impact of HPA axis dysfunction on the immune system see Webster et al., 2002; Elenkov, 2007) when the psychopathology results from increased activity of the right PFC.

\section{Take-home message}

There is now substantial evidence that the PFC is an important regulator of the behavioral and physiological reaction to stress. In addition, by extending the analysis of the stress response to different regions and assessing the function of the connections between them, we now have a better picture of how the effects of stress are integrated in the brain-beyond the hippocampus. Exposure to a stressor activates a network of tightly-interconnected brain areas that normally respond in a coordinated fashion. This coordination results from feedback between the different neural elements that comprise the so-called 'stress circuit'. (Fig. 1)

First and foremost, the stress response serves to help the organism to successfully adapt to changes in, and demands from, its environment through the sequential activation of selected neural circuits and physiological systems. In this respect, it is interesting to note that the PFC, which is implicated in several forms of working memory and behavioral flexibility, is consistently activated during the stress response. Failure to adapt appropriately may reflect the quality, intensity and chronicity of a given stressful event. Paradoxically, in some ways, the very same systems that are supposed to help re-establish equilibrium become the targets of the damaging effects of stress. Ultimately, several systems of the body directly (or indirectly) become the "victims' of a maladapted response to stress; in particular, there is an overactivation of the HPA axis, a feature which may constitute an endophenotype for stress-related disorders, including immunological disorders.

\section{Acknowledgments}

We thank Professors Joana Almeida Palha and Margarida Correia Neves (Health Sciences School, University of Minho), for helpful remarks on the manuscript. Authors' work was in part supported by grants from the Portuguese 
government Foundation for Science and Technology (FCT) - Project PTDC/SAU-NEU/72699/2006 - and Calouste Gulbenkian Foundation-Project JG/0495.

\section{References}

Bandler, R., Keay, K.A., Floyd, N., Price, J., 2000. Central circuits mediating patterned autonomic activity during active vs. passive emotional coping. Brain Res. Bull. 53, 95-104.

Barense, M.D., Fox, M.T., Baxter, M.G., 2002. Aged rats are impaired on an attentional set-shifting task sensitive to medial frontal cortex damage in young rats. Learn. Mem. 9, 191-201.

Barneoud, P., Neveu, P.J., Vitiello, S., Le Moal, M., 1987. Functional heterogeneity of the right and left cerebral neocortex in the modulation of the immune system. Physiol. Behav. 41, 525-530.

Birrell, J.M., Brown, V.J., 2000. Medial frontal cortex mediates perceptual attentional set shifting in the rat. J. Neurosci. 20, 4320-4324.

Carroll, B.J., Feinberg, M., Greden, J.F., Haskett, R.F., James, N.M., Steiner, M., Tarika, J., 1980. Diagnosis of endogenous depression. Comparison of clinical, research and neuroendocrine criteria. J. Affect. Disord. 2, 177-194.

Cerqueira, J.J., Catania, C., Sotiropoulos, I., Schubert, M., Kalisch, R., Almeida, O.F.X., Auer, D.P., Sousa, N., 2005. Corticosteroid status influences the volume of the rat cingulate cortex - a magnetic resonance imaging study. J. Psychiatr. Res. 39, 451-460.

Cerqueira, J.J., Mailliet, F., Almeida, O.F.X., Jay, T.M., Sousa, N., 2007a. The prefrontal cortex as a key target of the maladaptive response to stress. J. Neurosci. 27, 2781-2787.

Cerqueira, J.J., Pego, J.M., Ferreira, E., Almeida, A.A., Almeida, O.F.X., Sousa, N., 2007b. Glutamate antagonism prevents stress-induced cognitive deficits: evidence for region and receptor-type specific effects. Society for Neuroscience Abstracts Program No. 642.1.

Cerqueira, J.J., Taipa, R., Uylings, H.B., Almeida, O.F., Sousa, N., 2007c. Specific configuration of dendritic degeneration in pyramidal neurons of the medial prefrontal cortex induced by differing corticosteroid regimens. Cereb. Cortex 17, 1998-2006.

Chudasama, Y., Bussey, T.J., Muir, J.L., 2001. Effects of selective thalamic and prelimbic cortex lesions on two types of visual discrimination and reversal learning. Eur. J. Neurosci. 14, 1009-1020.

Chudasama, Y., Passetti, F., Rhodes, S.E., Lopian, D., Desai, A., Robbins, T.W., 2003. Dissociable aspects of performance on the 5choice serial reaction time task following lesions of the dorsal anterior cingulate, infralimbic and orbitofrontal cortex in the rat: differential effects on selectivity, impulsivity and compulsivity. Behav. Brain Res. 146, 105-119.

Chudasama, Y., Robbins, T.W., 2003. Dissociable contributions of the orbitofrontal and infralimbic cortex to pavlovian autoshaping and discrimination reversal learning: further evidence for the functional heterogeneity of the rodent frontal cortex. J. Neurosci. 23:, 8771-8780.

Chudasama, Y., Robbins, T.W., 2006. Functions of frontostriatal systems in cognition: comparative neuropsychopharmacological studies in rats, monkeys and humans. Biol. Psychol. 73, 19-38.

Clark, L., Manes, F., 2004. Social and emotional decision-making following frontal lobe injury. Neurocase 10, 398-403.

Dalley, J.W., Cardinal, R.N., Robbins, T.W., 2004. Prefrontal executive and cognitive functions in rodents: neural and neurochemical substrates. Neurosci. Biobehav. Rev. 28, 771-784.

Damasio, A.R., 2000. Eighth C.U. Ariens Kappers Lecture. The fabric of the mind: a neurobiological perspective. Prog. Brain Res. 126, 457467.

Davidson, R.J., Coe, C.C., Dolski, I., Donzella, B., 1999. Individual differences in prefrontal activation asymmetry predict natural killer cell activity at rest and in response to challenge. Brain Behav. Immun. 13, 93-108.

Davidson, R.J., 1998. Anterior electrophysiological asymmetries, emotion, and depression: conceptual and methodological conundrums. Psychophysiology 35, 607-614. de Bruin, J.P., 1990. Social behaviour and the prefrontal cortex. Prog. Brain Res. 85, 485-496.

Delatour, B., Gisquet-Verrier, P., 2000. Functional role of rat prelimbicinfralimbic cortices in spatial memory: evidence for their involvement in attention and behavioural flexibility. Behav. Brain Res. 109, 113128.

Denenberg, V.H., 1983. Lateralization of function in rats. Am. J. Physiol 245, R505-R509.

Diorio, D., Viau, V., Meaney, M.J., 1993. The role of the medial prefrontal cortex (cingulate gyrus) in the regulation of hypothalamicpituitary-adrenal responses to stress. J. Neurosci. 13, 3839-3847.

Divac, I., 1971. Frontal lobe system and spatial reversal in the rat. Neuropsychologia $9,175-183$.

Elenkov, I.J., 2007. Neurohormonal-cytokine interactions: implications for inflammation, common human diseases and well-being. Neurochem. Int., PMID 17716784.

Feldman, S., Conforti, N., 1985. Modifications of adrenocortical responses following frontal cortex simulation in rats with hypothalamic deafferentations and medial forebrain bundle lesions. Neuroscience 15, 1045-1047.

Frankel, R.J., Jenkins, J.S., 1975. Pituitary hormone response to brain stimulation in man. J. Endocrinol. 67, 113-117.

Frysztak, R.J., Neafsey, E.J., 1994. The effect of medial frontal cortex lesions on cardiovascular conditioned emotional responses in the rat. Brain Res. 643, 181-193.

Fu, Q.L., Shen, Y.Q., Gao, M.X., Dong, J., Neveu, P.J., Li, K.S., 2003. Brain interleukin asymmetries and paw preference in mice. Neuroscience 116, 639-647.

Fuster, J.M., 1997. The Prefrontal Cortex: Anatomy, Physiology and Neuropsychology of the Frontal Lobe. Raven Press, New York.

Gallagher, M., McMahan, R.W., Schoenbaum, G., 1999. Orbitofrontal cortex and representation of incentive value in associative learning. J. Neurosci. 19, 6610-6614.

Goel, V., Tierney, M., Sheesley, L., Bartolo, A., Vartanian, O., Grafman, J., 2007. Hemispheric specialization in human prefrontal cortex for resolving certain and uncertain inferences. Cereb. Cortex 17, 2245 2250.

Goldman-Rakic, P.S., 1995. Architecture of the prefrontal cortex and the central executive. Ann. N. Y. Acad. Sci. 769, 71-83.

Haddon, J.E., Killcross, S., 2006. Prefrontal cortex lesions disrupt the contextual control of response conflict. J. Neurosci. 26, 2933-2940.

Harper, R.M., Bandler, R., Spriggs, D., Alger, J.R., 2000. Lateralized and widespread brain activation during transient blood pressure elevation revealed by magnetic resonance imaging. J. Comp. Neurol. 417, 195204.

Holscher, C., 1999. Synaptic plasticity and learning and memory: LTP and beyond. J. Neurosci. Res. 58, 62-75.

Jinks, A.L., McGregor, I.S., 1997. Modulation of anxiety-related behaviours following lesions of the prelimbic or infralimbic cortex in the rat. Brain Res. 772, 181-190.

Johnstone, T., van Reekum, C.M., Urry, H.L., Kalin, N.H., Davidson, R.J., 2007. Failure to regulate: counterproductive recruitment of topdown prefrontal-subcortical circuitry in major depression. J. Neurosci. 27, 8877-8884.

Killcross, S., Coutureau, E., 2003. Coordination of actions and habits in the medial prefrontal cortex of rats. Cereb. Cortex 13, 400-408.

Koch, H.J., Uyanik, G., Bogdahn, U., Ickenstein, G.W., 2006. Relation between laterality and immune response after acute cerebral ischemia. Neuroimmunomodulation 13, 8-12.

Kolb, B., Buhrmann, K., McDonald, R., Sutherland, R.J., 1994 Dissociation of the medial prefrontal, posterior parietal, and posterior temporal cortex for spatial navigation and recognition memory in the rat. Cereb. Cortex 4, 664-680.

Kolb, B., Nonneman, A.J., Singh, R.K., 1974. Double dissociation of spatial impairments and perseveration following selective prefrontal lesions in rats. J. Comp. Physiol. Psychol. 87, 772-780.

Kolb, B., Nonneman, A.J., 1975. Prefrontal cortex and the regulation of food intake in the rat. J. Comp. Physiol. Psychol. 88, 806-815. 
Kolb, B., Whishaw, I.Q., 1983. Dissociation of the contributions of the prefrontal, motor, and parietal cortex to the control of movement in the rat: an experimental review. Can. J. Psychol. 37, 211-232.

Kolb, B., 1974a. Some tests of response habituation in rats with discrete lesions to the orbital or medial frontal cortex. Can. J. Psychol. 28, 260267.

Kolb, B., 1974b. Prefrontal lesions alter eating and hoarding behavior in rats. Physiol. Behav. 12, 507-511.

Kolb, B., 1974c. Dissociation of the effects of lesions of the orbital or medial aspect of the prefrontal cortex of the rat with respect to activity. Behav. Biol. 10, 329-343.

Kolb, B., 1974d. Social behavior of rats with chronic prefrontal lesions. J. Comp. Physiol. Psychol. 87, 466-474.

LaBuda, C.J., Fuchs, P.N., 2005. Attenuation of negative pain affect produced by unilateral spinal nerve injury in the rat following anterior cingulate cortex activation. Neuroscience 136, 311-322.

Laroche, S., Davis, S., Jay, T.M., 2000. Plasticity at hippocampal to prefrontal cortex synapses: dual roles in working memory and consolidation. Hippocampus 10, 438-446.

Lauterborn, J.C., Lynch, G., Vanderklish, P., Arai, A., Gall, C.M., 2000. Positive modulation of AMPA receptors increases neurotrophin expression by hippocampal and cortical neurons. J. Neurosci. 20, 8-21.

Lu, J., Goula, D., Sousa, N., Almeida, O.F., 2003. Ionotropic and metabotropic glutamate receptor mediation of glucocorticoid-induced apoptosis in hippocampal cells and the neuroprotective role of synaptic $N$-methyl-D-aspartate receptors. Neuroscience 121, 123-131.

MacLullich, A.M., Ferguson, K.J., Wardlaw, J.M., Starr, J.M., Deary, I.J., Seckl, J.R., 2006. Smaller left anterior cingulate cortex volumes are associated with impaired hypothalamic-pituitary-adrenal axis regulation in healthy elderly men. J. Clin. Endocrinol. Metab. 91, 1591-1594.

Meador, K.J., Loring, D.W., Ray, P.G., Helman, S.W., Vazquez, B.R., Neveu, P.J., 2004. Role of cerebral lateralization in control of immune processes in humans. Ann. Neurol. 55, 840-844.

Mizoguchi, K., Ishige, A., Aburada, M., Tabira, T., 2003. Chronic stress attenuates glucocorticoid negative feedback: involvement of the prefrontal cortex and hippocampus. Neuroscience 119, 887-897.

Mizoguchi, K., Yuzurihara, M., Ishige, A., Sasaki, H., Chui, D.H., Tabira, T., 2001. Chronic stress differentially regulates glucocorticoid negative feedback response in rats. Psychoneuroendocrinology 26, 443-459.

Mobini, S., Body, S., Ho, M.Y., Bradshaw, C.M., Szabadi, E., Deakin, J.F., Anderson, I.M., 2002. Effects of lesions of the orbitofrontal cortex on sensitivity to delayed and probabilistic reinforcement. Psychopharmacology (Berl.) 160, 290-298.

Muir, J.L., Everitt, B.J., Robbins, T.W., 1996. The cerebral cortex of the rat and visual attentional function: dissociable effects of mediofrontal, cingulate, anterior dorsolateral, and parietal cortex lesions on a fivechoice serial reaction time task. Cereb. Cortex 6, 470-481.

Neveu, P.J., 1992. Asymmetrical brain modulation of the immune response. Brain Res. Brain Res. Rev. 17, 101-107.

Neveu, P.J., Merlot, E., 2003. Cytokine stress responses depend on lateralization in mice. Stress 6, 5-9.

Otto, T., Eichenbaum, H., 1992. Complementary roles of the orbital prefrontal cortex and the perirhinal-entorhinal cortices in an odorguided delayed-nonmatching-to-sample task. Behav. Neurosci. 106, $762-775$.

Perrotti, L.I., Hadeishi, Y., Ulery, P.G., Barrot, M., Monteggia, L., Duman, R.S., Nestler, E.J., 2004. Induction of deltaFosB in rewardrelated brain structures after chronic stress. J. Neurosci. 24, 10594 10602.

Pirot, S., Jay, T.M., Glowinski, J., Thierry, A.M., 1994. Anatomical and electrophysiological evidence for an excitatory amino acid pathway from the thalamic mediodorsal nucleus to the prefrontal cortex in the rat. Eur. J. Neurosci. 6, 1225-1234.

Powell, D.A., Watson, K., Maxwell, B., 1994. Involvement of subdivisions of the medial prefrontal cortex in learned cardiac adjustments in rabbits. Behav. Neurosci. 108, 294-307.
Quaranta, A., Siniscalchi, M., Frate, A., Iacoviello, R., Buonavoglia, C., Vallortigara, G., 2006. Lateralised behaviour and immune response in dogs: relations between paw preference and interferon-gamma, interleukin-10 and IgG antibodies production. Behav. Brain Res. 166, 236240.

Quirk, G.J., Russo, G.K., Barron, J.L., Lebron, K., 2000. The role of ventromedial prefrontal cortex in the recovery of extinguished fear. $\mathbf{J}$. Neurosci. 20, 6225-6231.

Radley, J.J., Arias, C.M., Sawchenko, P.E., 2006. Regional differentiation of the medial prefrontal cortex in regulating adaptive responses to acute emotional stress. J. Neurosci. 26, 12967-12976.

Radley, J.J., Sisti, H.M., Hao, J., Rocher, A.B., McCall, T., Hof, P.R., McEwen, B.S., Morrison, J.H., 2004. Chronic behavioral stress induces apical dendritic reorganization in pyramidal neurons of the medial prefrontal cortex. Neuroscience 125, 1-6.

Ragozzino, M.E., Adams, S., Kesner, R.P., 1998. Differential involvement of the dorsal anterior cingulate and prelimbic-infralimbic areas of the rodent prefrontal cortex in spatial working memory. Behav. Neurosci. 112, 293-303.

Ragozzino, M.E., Kesner, R.P., 1999. The role of the agranular insular cortex in working memory for food reward value and allocentric space in rats. Behav. Brain Res. 98, 103-112.

Renoux, G., Bizière, K., Renoux, M., Guillaumin, J.M., Degenne, D., 1983. A balanced brain asymmetry modulates $\mathrm{T}$ cell-mediated events. J. Neuroimmunol. 5, 227-238.

Robinson, R.G., Kubos, K.L., Starr, L.B., Rao, K., Price, T.R., 1984. Mood disorders in stroke patients. Importance of location of lesion. Brain 107, 81-93.

Roozendaal, B., Okuda, S., de Quervain, D.J., McGaugh, J.L., 2006. Glucocorticoids interact with emotion-induced noradrenergic activation in influencing different memory functions. Neuroscience 138, 901910.

Rudolf, G.D., Cronin, C.A., Landwehrmeyer, G.B., Standaert, D.G., Penney Jr., J.B., Young, A.B., 1996. Expression of $N$-methyl-Daspartate glutamate receptor subunits in the prefrontal cortex of the rat. Neuroscience 73, 417-427.

Schoenbaum, G., Setlow, B., 2001. Integrating orbitofrontal cortex into prefrontal theory: common processing themes across species and subdivisions. Learn. Mem. 8, 134-147.

Sheline, Y.I., 2000. 3D MRI studies of neuroanatomic changes in unipolar major depression: the role of stress and medical comorbidity. Biol. Psychiatry 48, 791-800.

Shibata, H., 1993. Efferent projections from the anterior thalamic nuclei to the cingulate cortex in the rat. J. Comp. Neurol. 330, 533-542.

Silva, R., Lu, J., Wu, Y., Martins, L., Almeida, O.F.X., Sousa, N., 2006. Mapping cellular gains and losses in the postnatal dentate gyrus: implications for psychiatric disorders. Exp. Neurol. 200, 321-331.

Sousa, N., Cerqueira, J.J., Almeida, O.F.X., 2007. Corticosteroid receptors and neuroplasticity. Brain Res. Rev., PMID 17692926.

Sparkman, N.L., Buchanan, J.B., Heyen, J.R., Chen, J., Beverly, J.L., Johnson, R.W., 2006. Interleukin-6 facilitates lipopolysaccharideinduced disruption in working memory and expression of other proinflammatory cytokines in hippocampal neuronal cell layers. J. Neurosci. 26, 10709-10716.

Spencer, S.J., Ebner, K., Day, T.A., 2004. Differential involvement of rat medial prefrontal cortex dopamine receptors in modulation of hypothalamic-pituitary-adrenal axis responses to different stressors. Eur. J. Neurosci. 20, 1008-1016.

Sullivan, R.M., Gratton, A., 1999. Lateralized effects of medial prefrontal cortex lesions on neuroendocrine and autonomic stress responses in rats. J. Neurosci. 19, 2834-2840.

Sullivan, R.M., Gratton, A., 2002. Prefrontal cortical regulation of hypothalamic-pituitary-adrenal function in the rat and implications for psychopathology: side matters. Psychoneuroendocrinology 27, 99114.

Sullivan, R.M., 2004. Hemispheric asymmetry in stress processing in rat prefrontal cortex and the role of mesocortical dopamine. Stress 7, 131143. 
Swanson, L.W., Cowan, W.M., 1977. An autoradiographic study of the organization of the efferent connections of the hippocampal formation in the rat. J. Comp. Neurol. 172, 49-84.

Tichomirowa, M.A., Keck, M.E., Schneider, H.J., Paez-Pereda, M., Renner, U., Holsboer, F., Stalla, G.K., 2005. Endocrine disturbances in depression. J. Endocrinol. Invest. 28, 89-99.

Uylings, H.B., Groenewegen, H.J., Kolb, B., 2003. Do rats have a prefrontal cortex? Behav. Brain Res. 146, 3-17.

Vickers, J.C., Huntley, G.W., Edwards, A.M., Moran, T., Rogers, S.W., Heinemann, S.F., Morrison, J.H., 1993. Quantitative localization of AMPA/kainate and kainate glutamate receptor subunit immunoreactivity in neurochemically identified subpopulations of neurons in the prefrontal cortex of the macaque monkey. J. Neurosci. 13, 2982-2992.

Vidal-Gonzalez, I., Vidal-Gonzalez, B., Rauch, S.L., Quirk, G.J., 2006. Microstimulation reveals opposing influences of prelimbic and infralimbic cortex on the expression of conditioned fear. Learn. Mem. 13, 728-733.

Vlajković, S., Nikolić, V., Nikolić, A., Milanović, S., Janković, B.D., 1994. Asymmetrical modulation of immune reactivity in left- and right-biased rats after ipsilateral ablation of the prefrontal, parietal and occipital brain neocortex. Int. J. Neurosci. 78, 123-134.

Webster, J.I., Tonelli, L., Sternberg, E.M., 2002. Neuroendocrine regulation of immunity. Annu. Rev. Immunol. 20, 125-163.
Whishaw, I.Q., Pellis, S.M., Gorny, B.P., 1992a. Medial frontal cortex lesions impair the aiming component of rat reaching. Behav. Brain Res. 50, 93-104.

Whishaw, I.Q., Tomie, J.A., Kolb, B., 1992b. Ventrolateral prefrontal cortex lesions in rats impair the acquisition and retention of a tactileolfactory configural task. Behav. Neurosci. 106, 597-603.

Wikmark, R.G., Divac, I., Weiss, R., 1973. Retention of spatial delayed alternation in rats with lesions in the frontal lobes. Implications for a comparative neuropsychology of the prefrontal system. Brain Behav. Evol. 8, 329-339.

Winstanley, C.A., Theobald, D.E., Cardinal, R.N., Robbins, T.W., 2004 Contrasting roles of basolateral amygdala and orbitofrontal cortex in impulsive choice. J. Neurosci. 24, 4718-4722.

Wittling, W., 1997. The right hemisphere and the human stress response. Acta Physiol. Scand. 640, 55-59.

Wu, X., Zhu, D., Jiang, X., Okagaki, P., Mearow, K., Zhu, G., McCall, S., Banaudha, K., Lipsky, R.H., Marini, A.M., 2004. AMPA protects cultured neurons against glutamate excitotoxicity through a phosphatidylinositol 3-kinase-dependent activation in extracellular signalregulated kinase to upregulate BDNF gene expression. J. Neurochem. 90, 807-818.

Zilles, K., Wree, A., 1995. Cortex: areal and laminar structure. In: Paxinos, G. (Ed.), The Rat Nervous System. Academic Press, San Diego. 